\title{
Hydroxyapatite-Functionalized Graphene: A New Hybrid Nanomaterial
}

\author{
C. Rodríguez-González, ${ }^{1}$ H. E. Cid-Luna, ${ }^{1}$ P. Salas, ${ }^{1}$ and V. M. Castaño ${ }^{1,2}$ \\ ${ }^{1}$ Centro de Física Aplicada y Tecnología Avanzada, Universidad Nacional Autónoma de México, Boulevard Juriquilla 3001, \\ 76230 Santiago de Querétaro, QRO, Mexico \\ ${ }^{2}$ Centro de Tecnología Avanzada (CIATEQ), Avenida El Retablo 150, 76150 Santiago de Querétaro, QRO, Mexico
}

Correspondence should be addressed to V. M. Castaño; meneses@unam.mx

Received 26 March 2014; Accepted 16 June 2014; Published 20 July 2014

Academic Editor: John Z. Guo

Copyright (C) 2014 C. Rodríguez-González et al. This is an open access article distributed under the Creative Commons Attribution License, which permits unrestricted use, distribution, and reproduction in any medium, provided the original work is properly cited.

Graphene oxide sheets (GO) were functionalized with hydroxyapatite nanoparticles (nHAp) through a simple and effective hydrothermal treatment and a novel physicochemical process. Microstructure and crystallinity were investigated by Fourier transform infrared spectroscopy (FT-IR), Raman spectroscopy, X-ray diffraction (XRD), ultraviolet-visible (UV-Vis) absorption spectroscopy, and thermogravimetric analysis (TGA). Transmission electron microscopy (TEM) and scanning electron microscopy (SEM) were performed to characterize the morphology of the functionalized material. The resulting novel materials combine the biocompatibility of the nHAp with the strength and physical properties of the graphene.

\section{Introduction}

Graphene is a fascinating 2D nanomaterial whose importance has been recognized since it was isolated in 2004 [1]. This carbon allotrope, which consists of a single layer of carbon atoms covalently bonded in a hexagonal network, exhibits exceptional properties such as high mechanical strength, optimal thermal conductivity, and excellent electrical conductivity [2-4]. Since basically all atoms in its surface are exposed, graphene presents an extremely large specific surface area (theoretical value of $2600 \mathrm{~g} / \mathrm{m}^{2}$ ) making it an ideal candidate for the addition for various molecules [5, 6]. Moreover, graphene and graphene-related materials have shown potential biocompatibility, which is an essential issue if bioapplications, ranging from biomaterials to drug delivery systems, are to be considered [7-9].

Graphene oxide (GO) is a heavily oxygenated graphene derivative [10]. Structurally, graphene oxide sheets consist of graphene sheets decorated with epoxy, hydroxyl, and ketone functional groups, above and below each plane, as well as carboxyl and carbonyl functionalities attached to the edges of the sheets. The abundance of functional groups on the surface of GO makes it highly hydrophilic [11]. These functionalities can be used as chemical anchoring sites for different molecules, thus generating new composite materials with enhanced properties, as compared to their individual components [12-19].

Hydroxyapatite (HAp) is a compound made of calcium phosphate, the main crystalline component of the mineral phase of the bone [20]. Given its chemical and structural similarity with the biological apatite, the synthetic hydroxyapatite possesses exceptional biocompatibility and lack of toxicity $[21,22]$. In addition, HAp is osteoconductive; that is, it promotes bone-cells growth when it is placed in the vicinity of viable bone [20]. As a result, HAp is being widely used in coatings on metal implants, as a filling for bone defects in orthopedic and dental applications, and also as reinforcement to polymer scaffold material for tissue regeneration [23].

Accordingly, it seems very attractive to develop a new class of hybrid material integrating mechanical properties and biological activity, which is highly promising to be used as a scaffold to promote the growth and differentiation of several classes of cells. It can also be used as 
a biocompatible phase reinforcement in biomedical composites and a drug delivery carrier [8], by synergetically combining GO and HAp. However, to date, there are few reports on methods for the fabrication of a GO-HAp nanocomposite. Neelgund et al., for instance, reported the functionalization of graphene sheets with hydroxyapatite through chemical precipitation [24]. Liu et al. showed the simultaneous surface modification and reduction of GO sheets by polymerization of dopamine and then deposited the hydroxyapatite onto this surface by using a biomineralization method [25]. Kim et al. synthesized graphene oxide- $\mathrm{CaCO}_{3}$ vaterite microspheres hybrid film, which enhanced hydroxyapatite formation when incubated in simulated body fluid solution [26]. Liu et al. reported the synthesis of reduced graphene oxide and hydroxyapatite composite by chemical precipitation followed by spark plasma sintering consolidation [27].

Hydrothermal processing offers an interesting and effective route to synthesize nanocomposite materials using gentle reaction conditions. This approach produces highly crystalline and chemically homogeneous hydroxyapatite nanoparticles. Previous reports have also demonstrated it is convenient method for the reduction of graphene oxide sheets [28-30].

In this present study, we report the surface functionalization of graphene oxide sheets with hydroxyapatite through a low temperature hydrothermal synthesis. To the best of our knowledge, this synthesis method has not been reported yet. In our process, the influence of hydrothermal reaction time on the morphology of functionalized material was observed. The graphene-based hybrid material was morphological and microstructural characterized.

\section{Materials and Methods}

2.1. Materials. Pure crystalline graphite (300 meshes) was purchased from Electron Microscopy Science. Ammonium hydroxide $\left(\mathrm{NH}_{4} \mathrm{OH}\right)$ and diammonium hydrogen phosphate $\left(\left(\mathrm{NH}_{4}\right)_{2} \mathrm{HPO}_{4}\right)$ were obtained from Baker. All other reagents and solvents were obtained from Aldrich. All of the reagents were of analytical grade and used without any further purification.

2.2. GO Functionalization with HAp Nanoparticles. GO was synthesized by the modified Hummers method [11]. A typical experiment, for the functionalization of GO with HAp nanoparticles, is as follows: $45 \mathrm{mg}$ GO was dispersed in $15 \mathrm{~mL}$ DI water by ultrasonic treatment for $3 \mathrm{~h}$. Then, $4.475 \mathrm{~mL}$ of $\mathrm{Ca}\left(\mathrm{NO}_{3}\right)_{2} \cdot 4 \mathrm{H}_{2} \mathrm{O}(0.1 \mathrm{M})$ and $2.685 \mathrm{~mL}$ of $\left(\mathrm{NH}_{4}\right)_{2} \mathrm{HPO}_{4}$ $(0.1 \mathrm{M})$ were added to the above system, obtaining the molar $\mathrm{Ca} / \mathrm{P}$ ratio of 1.6 , which corresponds to pure hydroxyapatite ratio. Furthermore, $\mathrm{NH}_{4} \mathrm{OH}$ was dropped in excess under constant stirring, adjusting the $\mathrm{pH}$ of the suspension to $\approx 10$. The mixture was then transferred to a $70 \mathrm{~mL}$ teflonlined autoclave and heated at $90^{\circ} \mathrm{C}$ under autogenous pressure for 6 and 24 hours. The hydrothermal synthesis of pure calcium hydroxyphosphate was based on the following reaction:

$$
\begin{aligned}
& 10 \mathrm{Ca}\left(\mathrm{NO}_{3}\right)_{2}+6\left(\mathrm{NH}_{4}\right)_{2} \mathrm{HPO}_{4}+8 \mathrm{NH}_{4} \mathrm{OH} \\
& \quad \longrightarrow \mathrm{Ca}_{10}\left(\mathrm{PO}_{4}\right)_{6}(\mathrm{OH})_{2}+20 \mathrm{NH}_{4} \mathrm{NO}_{3}+6 \mathrm{H}_{2} \mathrm{O}
\end{aligned}
$$

The resulting suspension was naturally cooled to room temperature and washed with deionized water several times, in order to remove the $\mathrm{NH}_{4} \mathrm{NO}_{3}$. Finally, the sample was dried at room temperature for $24 \mathrm{~h}$. In order to compare the obtained functionalized materials, pure HAp nanoparticles were also prepared by the same method.

2.3. Characterization. The crystallinity and phase purity of the products were examined by powder X-ray diffraction (XDR) in a Rigaku Miniflex diffractometer with $\mathrm{Cu} \mathrm{Ka}$ radiation $(\lambda=0.15418 \mathrm{~nm})$. Fourier transform infrared (FTIR) spectra of $\mathrm{KBr}$ powder pressed pellets were recorded on a Bruker VECTOR 33 within the spectral region 400 to $4000 \mathrm{~cm}^{-1}$. Transmission electron microscopy (TEM) images were taken with a JEOL JEM1010 microscope. The morphology and elemental analysis of nanomaterial were carried out using a scanning electron microscopy (SEM) JEOL JSM-6060 LV equipped with an energy dispersive X-ray spectroscopy (EDX) spectrometer Oxford Inca X-Sight. Raman analysis was performed at room temperature using a LabRAM Dilor micro-Raman system equipped with an Argon ion laser with a wavelength of $488 \mathrm{~nm}$. The absorption spectra of the samples were obtained using an ultraviolet visible spectroscopy (UV-Vis) recorded on a Hach spectrophotometer DR 5000. Thermal properties of GO and RGO/HA were measured by thermogravimetric analysis (TGA) on a SDT Q600 (TA Instruments) under a nitrogen atmosphere at a heating rate of $10^{\circ} \mathrm{C} / \mathrm{min}$.

\section{Results and Discussion}

FTIR was performed to verify GO reduction and functionalization with HAp nanoparticles, by the hydrothermal reaction. The characteristic absorption bands of GO (Figure 1(a)), including alkoxy $\mathrm{C}-\mathrm{O}$ stretching $\left(1030 \mathrm{~cm}^{-1}\right)$, epoxy C$\mathrm{O}$ stretching $\left(1247 \mathrm{~cm}^{-1}\right)$, O-H deformation vibrations of tertiary C-OH $\left(1400 \mathrm{~cm}^{-1}\right)$, and $\mathrm{C}=\mathrm{O}$ stretching $\left(1724 \mathrm{~cm}^{-1}\right)$, were identified. Also, a strong and broad absorption at $3350 \mathrm{~cm}^{-1}$, due to $\mathrm{O}-\mathrm{H}$ stretching vibrations, and an intense band at $1614 \mathrm{~cm}^{-1}$ corresponding to the $\mathrm{C}=\mathrm{C}$ benzene ring mode was observed [31]. As to the spectrum of prepared HAp (Figure 1(b)), the bands at 1035 and $1093 \mathrm{~cm}^{-1}$ correspond to the $\nu 3 \mathrm{PO}_{4}{ }^{3-}$ asymmetric stretching; 603 and $567 \mathrm{~cm}^{-1}$ are $\nu 4 \mathrm{PO}_{4}{ }^{3-}$ antisymmetric deformation [32]. The peaks at 3570 and $631 \mathrm{~cm}^{-1}$ derive from the stretching and librational modes of the $\mathrm{OH}$-ions, respectively [33]. After hydrothermal reaction, both spectra of RGO/HAp 6 and $24 \mathrm{~h}$ (Figures 1(c) and $1(\mathrm{~d})$ ) showed that bands for oxygen functional groups of GO were significantly reduced and some of them disappeared entirely. Moreover, a new absorption band appeared at $1560 \mathrm{~cm}^{-1}$, which may be attributed to the $\mathrm{C}=\mathrm{C}$ stretch vibration of graphene sheets [34]. The absence of the $\mathrm{O}-\mathrm{H}$ 


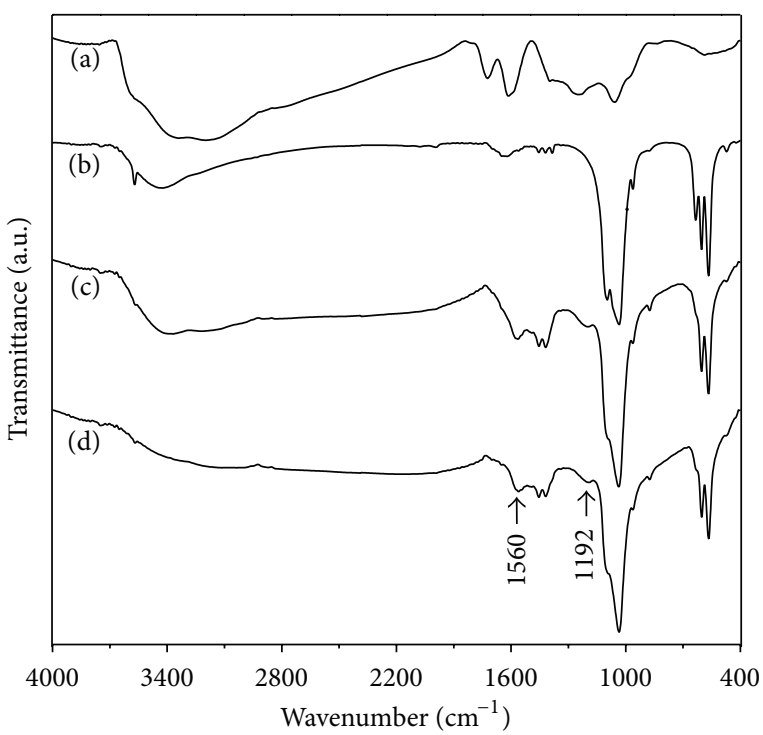

FIGURE 1: FT-IR spectra of GO (a), HAp (b), RGO/HAp 6 h (c), and RGO/HAp 24 h (d).

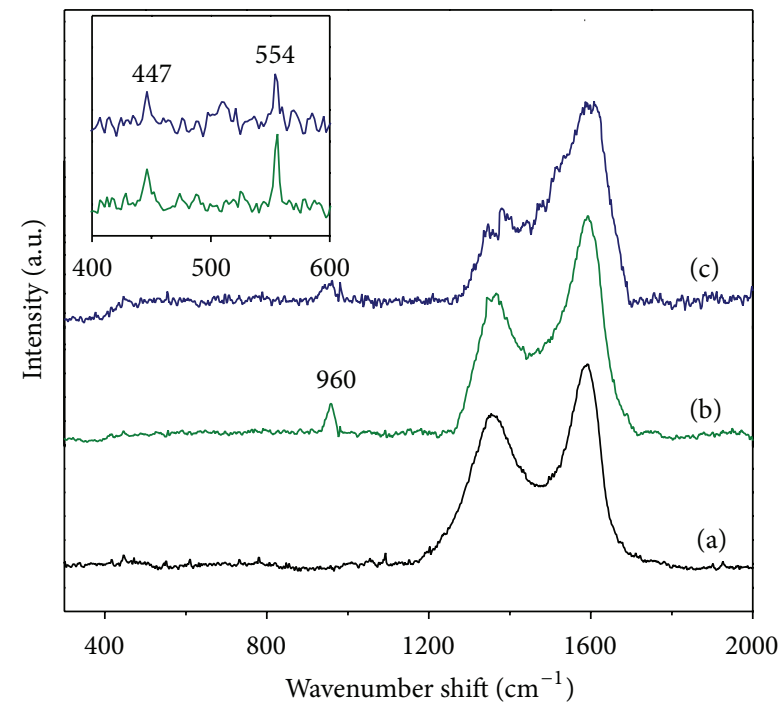

FIGURE 2: Raman spectra of pristine GO sheets (a), RGO/HAp 6 (b) and $24 \mathrm{~h}(\mathrm{c})$. Inset shows an amplification of RGO/HAp 6 and $24 \mathrm{~h}$.

band at $631 \mathrm{~cm}^{-1}$, compared to Hap and the appearance of the $\mathrm{C}-\mathrm{O}$ stretch band at $1192 \mathrm{~cm}^{-1}$, provided a solid indication of graphene oxide reduction and formation of the RGO/HAp composite. The spectrum of RGO/HAp at $24 \mathrm{~h}$ shows an increase in the width of the band at $1035\left(\mathrm{PO}_{4}{ }^{3-}\right)$ and a decrease in the band at $3570 \mathrm{~cm}^{-1}(\mathrm{O}-\mathrm{H})$, which could be attributed to an enhancement of the HAp particles on the GO surface.

Figure 2 shows the Raman spectra of GO (a) and HApgraphene after 6 (b) and 24 (c) hours of hydrothermal reaction. For GO there are two characteristic peaks in the spectra, the $G$ band at $1590 \mathrm{~cm}^{-1}$ and the $D$ band at $1353 \mathrm{~cm}^{-1}$. The $\mathrm{G}$ band is associated with the $E_{2 g}$ mode of graphite, which

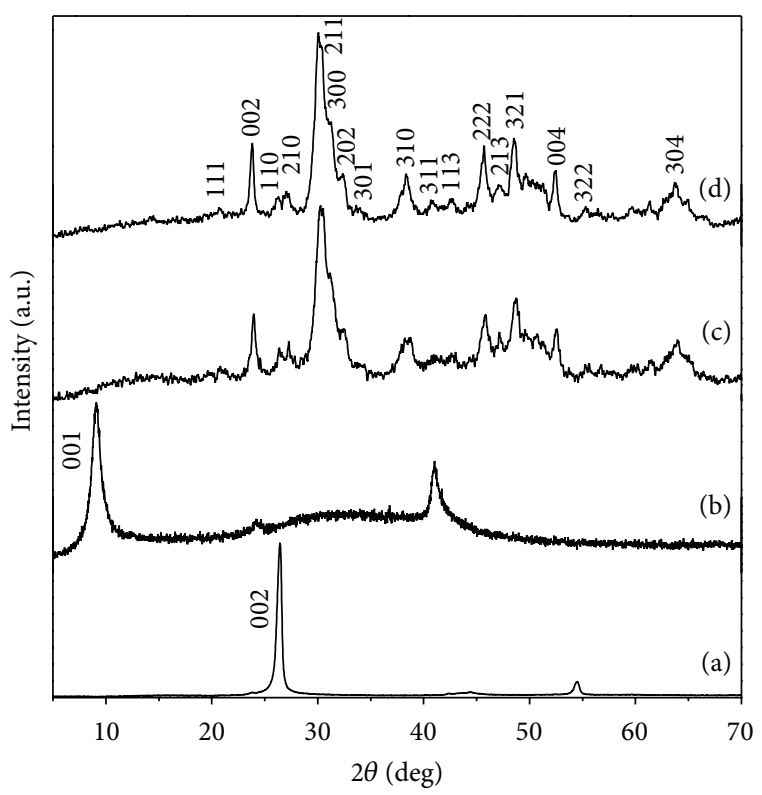

FIGURE 3: XRD patterns of pristine graphite (a), GO (b), RGO/HAp 6 (c) and $24 \mathrm{~h} \mathrm{(d).}$

is usually related to the in-phase vibrations of the graphite lattice, whereas the $D$ band is ascribed to the presence of disorder, vacancies, and edges in the $s p^{2}$ network $[35,36]$. In the Raman spectra of HAp-graphene $6 \mathrm{~h}$ and $24 \mathrm{~h}$ the $G$ band was shifted towards $1601 \mathrm{~cm}^{-1}$, while the intensity of the $D$ band decreased substantially. The shifting of the $G$ band may be due to the fact that the chemical interactions between carbon atoms of GO and reactive sites of HAp allow the formation of isolated double bonds, which resonate at higher frequencies [37]. The disorder and graphitization degree of carbon materials may be quantified by analyzing the $I D / I G$ intensity ratio between $D$ and $G$ band [36]. The $I D / I G$ ratios of GO, HAp-graphene 6 and $24 \mathrm{~h}$ were $1.03,0.53$, and 0.32 , respectively, indicating that the functionalization of graphene with HAp greatly enhances the size of the inplane $s p^{2}$ domains of GO [38]. In both HAp-graphene 6 and $24 \mathrm{~h}$ spectra the characteristic peaks for HAp at $447 \mathrm{~cm}^{-1}(\nu 2$ $\left.\left(\mathrm{PO}_{4}{ }^{3-}\right)\right), 554 \mathrm{~cm}^{-1}\left(\nu 4\left(\mathrm{PO}_{4}{ }^{3-}\right)\right)$, and $960 \mathrm{~cm}^{-1}\left(\nu 1\left(\mathrm{PO}_{4}{ }^{3-}\right)\right)$ $[34,39]$ were shown.

Figure 3 shows the XRD patterns of graphite (a), GO (b), and RGO/HAp $6 \mathrm{~h}$ (c) and $24 \mathrm{~h}$ (d). Graphite showed the characteristic (002) peak at around $2 \theta=26.4^{\circ}$, corresponding to an average interlayer spacing of $\sim 3.3 \AA$. The pattern of GO displayed the most intense peak at $2 \theta=$ $11.9^{\circ}$ which corresponds to the (001) reflection. Due to the presence of oxygen-containing functional groups attached on both sides of the graphene sheet, GO has an average interlayer spacing of $\sim 7.9 \AA$, indicating that individual graphene oxide sheets are thicker than pristine graphene sheets [40]. The diffraction patterns of both RGO/HAp 6 and $24 \mathrm{~h}$ show characteristic peaks of the HAp hexagonal phase (JCPDS, card number 9-432). Well-defined peaks appeared at $2 \theta$ around $25.9^{\circ}, 31.9^{\circ}, 32.9^{\circ}, 34.1^{\circ}, 39.8^{\circ}, 46.7^{\circ}$, and $50.5^{\circ}$, which are attributed, respectively, to the (002), 


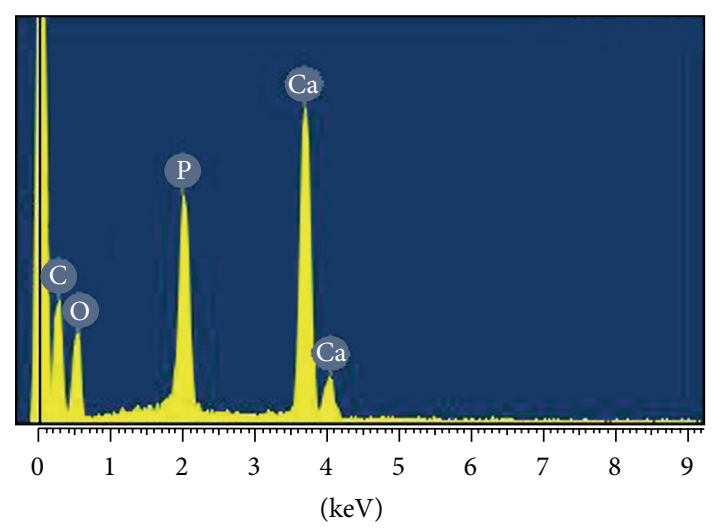

Full scale 527 cts Cursor: $0.021 \mathrm{keV}$ (801 cts)

FigURE 4: EDX spectrum of RGO/HAp after 24 hours of hydrothermal treatment.

(211), (300), (202), (310), (222), and (321) reflections of HA $[41,42]$. The average particle size of HAp nanoparticles was calculated to be ca. 8.3 and $9.5 \mathrm{~nm}$ for RGO/Hap 6 and $24 \mathrm{~h}$, respectively, based on Scherrer's equation. No signal for any other phases about GO (001) can be detected in the RGO/HAp composite (Figure 3(c)). This may be due to the fact that GO can be reduced to graphene during the hydrothermal reaction, producing a restacking of the sheets forming poorly ordered graphitic structures; consequently, their diffraction peaks might also turn weak until disappearing [43]. Moreover, because of functionalization, HAp nanoparticles act as spacers between graphene layers, which cannot be stacked to form detectable graphite structures; consequently, this weakens the diffraction of single carbon sheets [44].

RGO/HAp EDX spectrum (Figure 4) showed defined Ca, $\mathrm{P}, \mathrm{C}$, and $\mathrm{O}$ peaks that can be attributed to the presence of $\mathrm{GO}$ and HAp. Furthermore the $\mathrm{Ca} / \mathrm{P}$ atomic ratio of the composite was 1.66, which is lower than the stoichiometric composition of pure hydroxyapatite but close to the calcium-deficient HAp, present in natural bone tissue [45].

The UV-Vis spectra for GO and graphene-based hybrids dispersions are shown in Figure 5. The spectrum obtained for GO dispersion displays a maximum absorption peak at $230 \mathrm{~nm}$, which is characteristic of $\pi-\pi^{*}$ of aromatic $\mathrm{C}=\mathrm{C}$ bonds, and a shoulder at about $300 \mathrm{~nm}$ attributed to $n-\pi^{*}$ transitions of C-O bonds [46]. When the GO is functionalized with HAp nanoparticles, the peak at $230 \mathrm{~nm}$ is red shifted to $252 \mathrm{~nm}$ while the shoulder at $300 \mathrm{~nm}$ disappeared. This result suggests a strong interaction between graphene sheets and HAp nanoparticles and also the reduction of graphene oxide sheets $[46,47]$.

According to Figure 6(a), large and transparent graphene oxide sheets can be clearly observed in the TEM micrographs. The GO sheets exhibit wrinkled and crumpling morphologies illustrating a flake-like shape. The TEM images of RGO/HAp $6 \mathrm{~h}$ and RGO/HAp $24 \mathrm{~h}$ hybrid materials are shown in Figures 6(b) and 6(c), respectively. It is clearly seen in Figure 6(b)

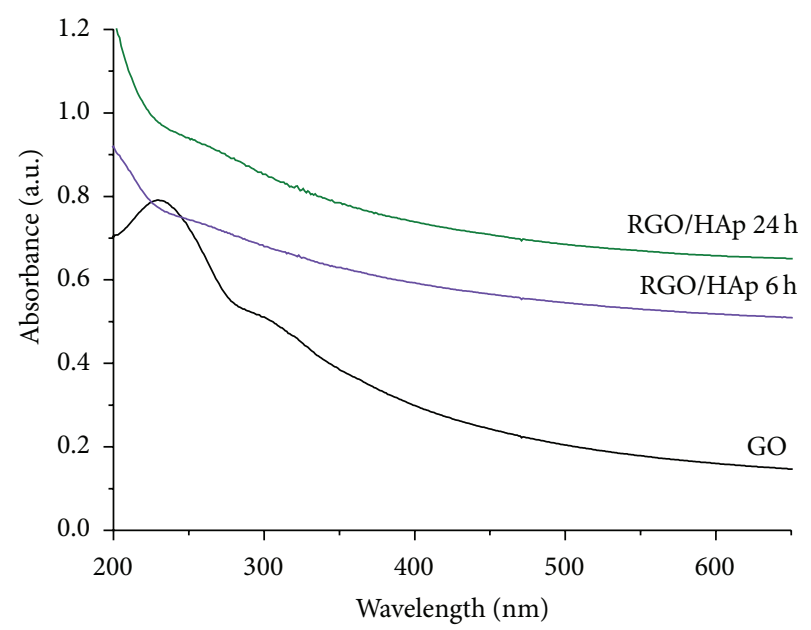

Figure 5: UV-Vis spectra of GO, RGO/HAp $6 \mathrm{~h}$, and RGO/HAp $24 \mathrm{~h}$.

that rod-like HAp nanoparticles are well separated and distributed randomly onto the transparent graphene oxide sheets, indicating a strong interaction between graphene and nanoparticles $[48,49]$. Figure 6(c) reveals graphene sheets uniformly decorated by the nanosized HAp particles. Also, the nanocomposite displays a high density of HAp nanoparticles. It is interesting to note that HAp nanoparticles are successfully dispersed onto graphene sheets in both hydrothermal reaction conditions. However, the density of HAp nanoparticles is higher in RGO/HAp $24 \mathrm{~h}$ nanocomposite because this hybrid material is subjected to a higher reaction time.

The SEM micrograph of Figure 7(a) displays layers of GO exhibiting a homogeneous surface with the characteristic wrinkles and ripples of graphene 2D structure. SEM images of RGO/HAp 6 h y RGO/HAp 24h, Figures 7(b) and 7(c), respectively, show a completely different morphology as compared with the GO sheets. In both hybrid materials it can be observed that HAp nanoparticles are homogeneously deposited onto the graphene sheets. The surface of these nanocomposites shows a rough structure with many granules, indicating that GO sheets are covered by nHAp. These results are consistent with the results obtained by TEM, which showed a homogeneous distribution of HAp nanoparticles onto graphene oxide surface indicating that hydrothermal approach is an effective method to form graphene-based hybrid materials.

The TGA curve of GO (Figure 8(c)) showed an initial weight loss (12 wt\%) before $100^{\circ} \mathrm{C}$ attributed to evaporation of water molecules contained in the material. The successive mass losses occurred below $250^{\circ} \mathrm{C}$ and above $550^{\circ} \mathrm{C}$, which are attributed to the decomposition of labile oxygen-containing functional groups and the pyrolysis of the carbon skeleton, respectively [50]. Compared with the GO weight loss at $250^{\circ} \mathrm{C}$ ( $40 \mathrm{wt} \%$ ), the weight loss of RGO/HAp (Figure $8(\mathrm{~b})$ ) at $250^{\circ} \mathrm{C}$ is much lower (9 wt\%), indicating a decreased amount of oxygenated functional groups after hydrothermal reduction. As for the TGA curve of HAp 


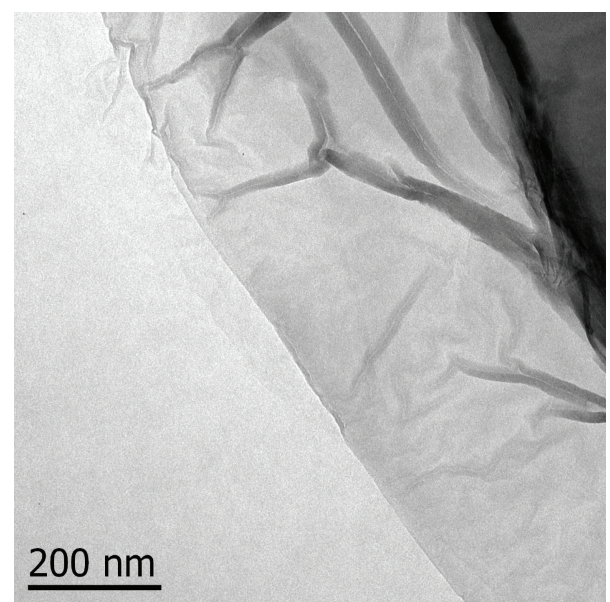

(a)

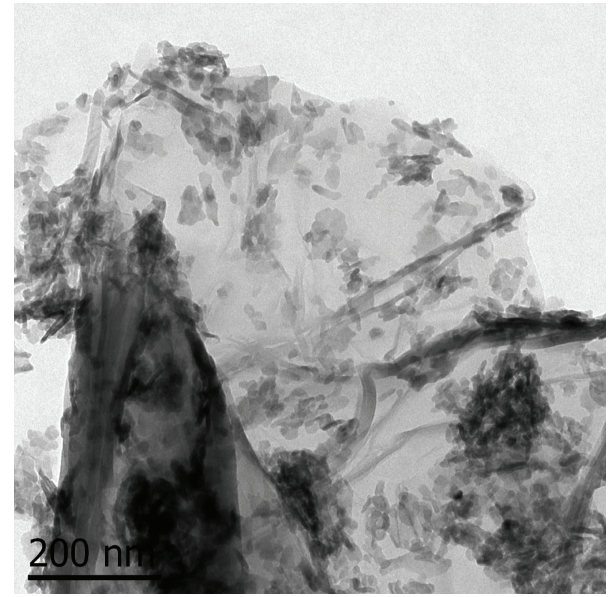

(b)

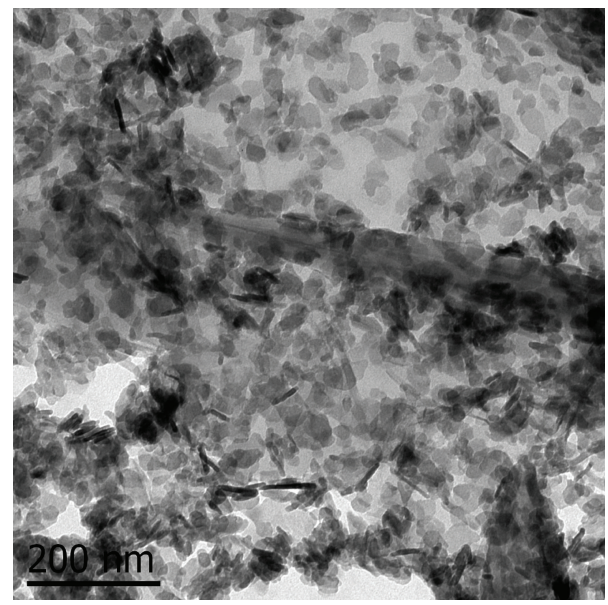

(c)

FIGURE 6: TEM images of graphene oxide (a), RGO/HAp $6 \mathrm{~h}$ (b), and RGO/HAp $24 \mathrm{~h}$ (c) of hydrothermal treatment.

(Figure 8(a)), there is no significant weight loss from room temperature up to $1000^{\circ} \mathrm{C}$, which is consistent with that reported in the literature [51]. The curve of RGO/HAp (Figure 8(b)) showed that the sample had lost a significant

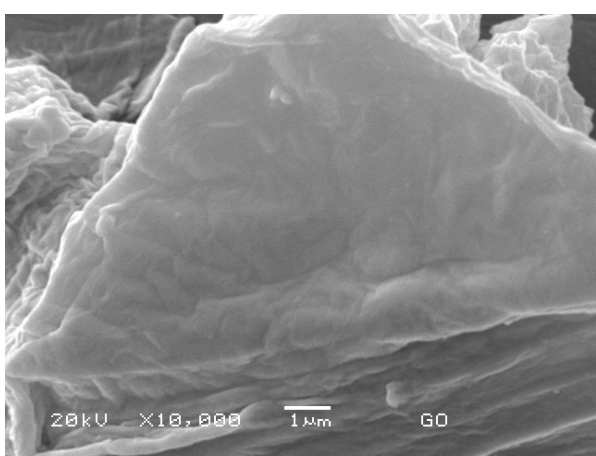

(a)

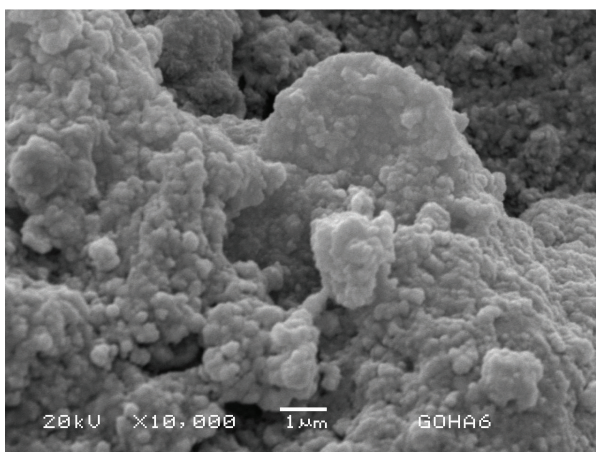

(b)

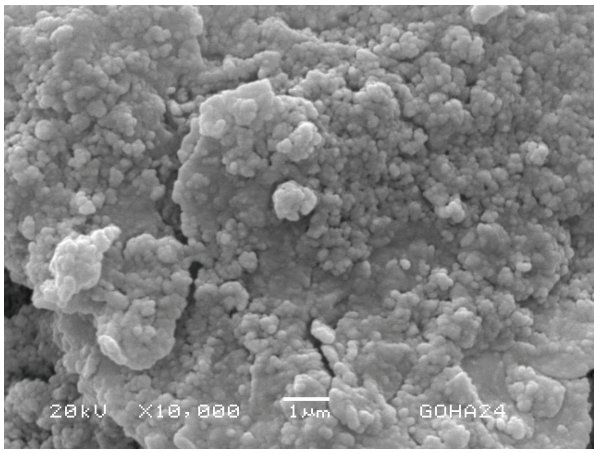

(c)

FIGURE 7: SEM images of GO sheets (a), RGO/HAp $6 \mathrm{~h}$ (b), and RGO/HAp 24 h (c).

mass ( $42 \mathrm{wt} \%$ ) from 550 to $880^{\circ} \mathrm{C}$, possibly due to the decomposition of graphene sheets. The residual weight measured for $\mathrm{GO}$ and $\mathrm{RGO} / \mathrm{HAp}$ at $1000^{\circ} \mathrm{C}$ was found to be $4 \mathrm{wt} \%$ and $58 \mathrm{wt} \%$, respectively, indicating the deposition of HAp nanoparticles over GO. Due to the thermal stability of HAp and after subtracting the water effect, it is estimated that about $61 \mathrm{wt} \%$ of $\mathrm{HA}$ is contained in the RGO/HAp composite.

\section{Conclusions}

Graphene oxide sheets were functionalized with hydroxyapatite nanoparticles through a hydrothermal reaction between $\mathrm{Ca}\left(\mathrm{NO}_{3}\right)_{2} \cdot 4 \mathrm{H}_{2} \mathrm{O}$ and $\left(\mathrm{NH}_{4}\right)_{2} \mathrm{HPO}_{4}$ in basic conditions at a temperature of $90^{\circ} \mathrm{C}$. Both conditions of hydrothermal reaction time $(6 \mathrm{~h}$ and $24 \mathrm{~h})$ produce the deposition of 


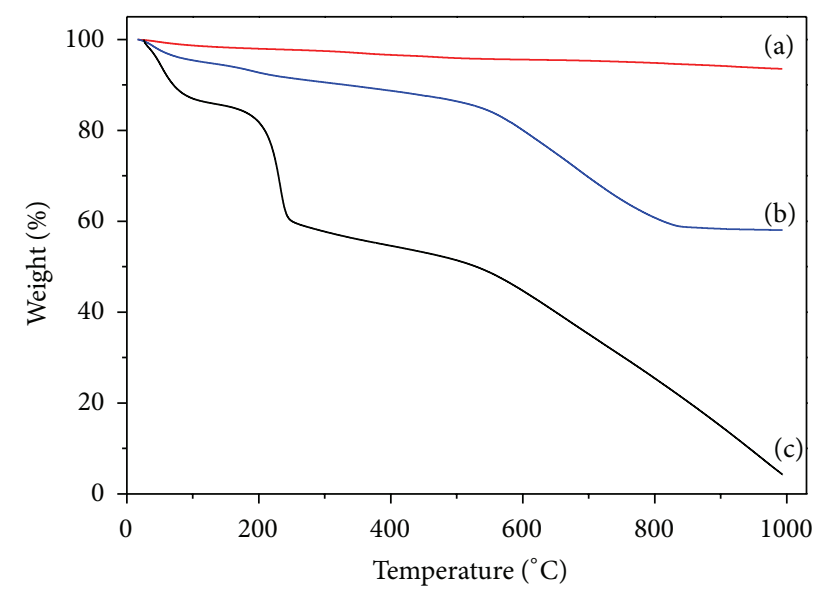

FIGURE 8: TGA profiles of HAp nanoparticles (a), GO sheets (c), and RGO/HAp (b) after $24 \mathrm{~h}$ of hydrothermal treatment.

hydroxyapatite nanoparticles free of impurities and other phases of calcium phosphates. However, a hydrothermal treatment time of $24 \mathrm{~h}$ produces graphene sheets highly decorated with nanohydroxyapatite with an average particle size $(9.5 \mathrm{~nm})$, larger in size compared to the ones obtained with a reaction time of $6 \mathrm{~h}$. The results suggest that the hydrothermal process produced the functionalization and reduction of GO sheets to graphene, simultaneously.

\section{Conflict of Interests}

The authors declare that there is no conflict of interests regarding the publication of this paper.

\section{Acknowledgments}

The authors are grateful to Beatriz M. Millán-Malo for assistance with the XRD analysis, Genoveva HernándezPadrón for FTIR analysis, Alicia del Real López for assistance with EDX and SEM, Ma. Lourdes Palma-Tirado for the TEM images, Damaris Cabrero-Palomino for TGA analysis, Francisco Rodríguez-Melgarejo for Raman analysis, and Ma. Cristina Piña-Barba for technical support. Claramaría Rodríguez-González is recipient of a postdoctoral fellowship from DGAPA/UNAM.

\section{References}

[1] K. S. Novoselov, A. K. Geim, S. V. Morozov et al., "Electric field in atomically thin carbon films," Science, vol. 306, no. 5696, pp. 666-669, 2004.

[2] C. Lee, X. Wei, J. W. Kysar, and J. Hone, "Measurement of the elastic properties and intrinsic strength of monolayer graphene," Science, vol. 321, no. 5887, pp. 385-388, 2008.

[3] A. A. Balandin, S. Ghosh, W. Bao et al., "Superior thermal conductivity of single-layer graphene," Nano Letters, vol. 8, pp. 902-907, 2008.

[4] R. M. Westervelt, “Graphene nanoelectronics,” Science, vol. 320, pp. 324-325, 2008.
[5] S. Zhang, K. Yang, L. Feng, and Z. Liu, "In vitro and in vivo behaviors of dextran functionalized graphene," Carbon, vol. 49, pp. 4040-4049, 2011.

[6] T. Kuila, S. Bose, A. K. Mishra, P. Khanra, N. H. Kim, and J. H. Lee, "Chemical functionalization of graphene and its applications," Progress in Materials Science, vol. 57, no. 7, pp. 1061-1105, 2012.

[7] Y. Chang, S. T. Yang, J. H. Liu et al., "In vitro toxicity evaluation of graphene oxide on A549 cells," Toxicology Letters, vol. 200, pp. 201-210, 2011.

[8] K. Yang, H. Gong, X. Shi, J. Wan, Y. Zhang, and Z. Liu, "In vivo biodistribution and toxicology of functionalized nanographene oxide in mice after oral and intraperitoneal administration," Biomaterials, vol. 34, pp. 2787-2795, 2013.

[9] K. H. Liao, Y. S. Lin, C. W. Macosko, and C. L. Haynes, “Cytotoxicity of graphene oxide and graphene in human erythrocytes and skin fibroblasts," ACS Applied Materials and Interfaces, vol. 3, pp. 2607-2615, 2011.

[10] S. K. Singh, M. K. Singh, P. P. Kulkarni, V. K. Sonkar, J. J. A. Grácio, and D. Dash, "Amine-modified graphene: thromboprotective safer alternative to graphene oxide for biomedical applications," ACS Nano, vol. 6, pp. 2731-2740, 2012.

[11] S. Stankovich, R. D. Piner, S. T. Nguyen, and R. S. Ruoff, "Synthesis and exfoliation of isocyanate-treated graphene oxide nanoplatelets," Carbon, vol. 44, pp. 3342-3347, 2006.

[12] C. Shan, H. Yang, D. Han, Q. Zhang, A. Ivaska, and L. Niu, "Water-soluble graphene covalently functionalized by biocompatible poly-l-lysine," Langmuir, vol. 25, pp. 12030-12033, 2009.

[13] S. Park, D. A. Dikin, S. T. Nguyen, and R. S. Ruoff, "Graphene oxide sheets chemically cross-linked by polyallylamine," The Journal of Physical Chemistry C, vol. 113, no. 36, pp. 15801-15804, 2009.

[14] R. Deepachitra, M. Chamundeeswari, B. Santhoshkumar et al., "Osteo mineralization of fibrin-decorated graphene oxide," Carbon, vol. 56, pp. 64-76, 2013.

[15] L. Shao, X. Cheng, Z. Wang, J. Ma, and Z. Guo, "Tuning the performance of polypyrrole-based solvent-resistant composite nanofiltration membranes by optimizing polymerization conditions and incorporating graphene oxide," Journal of Membrane Science, vol. 452, pp. 82-89, 2014.

[16] J. Zhu, M. Chen, H. Qu et al., "Magnetic field induced capacitance enhancement in graphene and magnetic graphene nanocomposites," Energy and Environmental Science, vol. 6, pp. 194204, 2013.

[17] H. Wei, J. Zhu, S. Wu, S. Wei, and Z. Guo, "Electrochromic polyaniline/graphite oxide nanocomposites with endured electrochemical energy storage," Polymer, vol. 54, pp. 1820-1831, 2013.

[18] J. Zhu, M. Chen, H. Qu et al., "Interfacial polymerized polyaniline/graphite oxide nanocomposites toward electrochemical energy storage," Polymer, vol. 53, pp. 5953-5964, 2012.

[19] L. Shao, X. Chang, Y. Zhang, Y. Huang, Y. Yao, and Z. Guo, "Graphene oxide cross-linked chitosan nanocomposite membrane," Applied Surface Science, vol. 280, pp. 989-992, 2013.

[20] B. D. Ratner, A. S. Hoffman, F. J. Schoen, and J. E. Lemons, Biomaterials Science: A Multidisciplinary Endeavor, Elsevier: Academic Press, New York, NY, USA, 2nd edition, 2004.

[21] M. P. Ferraz, F. J. Monteiro, and C. M. Manuel, "Hydroxyapatite nanoparticles: a review of preparation methodologies," Journal of Applied Biomaterials and Biomechanics, vol. 2, pp. 74-80, 2004. 
[22] M. Jevtic, M. Mitric, S. S. Kapin, B. Jancar, N. Ignjatovic, and D. Uskokovic, "Crystal structure of hydroxyapatite nanorods synthesized by sonochemical homogeneous precipitation. Cryst," Crystal Growth \& Design, vol. 8, pp. 2117-2222, 2008.

[23] D. Lahiri, S. Ghosh, and A. Agarwal, "Carbon nanotube reinforced hydroxyapatite composite for orthopedic application: a review," Materials Science and Engineering: C, vol. 32, no. 7, pp. 1727-1758, 2012.

[24] G. M. Neelgund, A. Oki, and Z. Luo, "In situ deposition of hydroxyapatite on graphene nanosheets," Materials Research Bulletin, vol. 48, pp. 175-179, 2013.

[25] H. Liu, P. Xi, G. Xie et al., "Simultaneous reduction and surface functionalization of graphene oxide for hydroxyapatite mineralization," The Journal of Physical Chemistry C, vol. 116, pp. 33343341, 2012.

[26] S. Kim, S. H. Ku, S. Y. Lim, J. H. Kim, and C. B. Park, "Graphene-biomineral hybrid materials," Advanced Materials, vol. 23, no. 17, pp. 2009-2014, 2011.

[27] Y. Liu, J. Huang, and H. Li, "Synthesis of hydroxyapatitereduced graphite oxide nanocomposites for biomedical applications: oriented nucleation and epitaxial growth of hydroxyapatite," Journal of Materials Chemistry B, vol. 1, no. 13, pp. 18261834, 2013.

[28] I. S. Neira, Y. V. Kolen'ko, O. I. Lebedev et al., "An effective morphology control of hydroxyapatite crystals via hydrothermal synthesis," Crystal Growth \& Design, vol. 9, no. 1, pp. 466474, 2009.

[29] J. Shen, B. Yan, M. Shi, H. Ma, N. Li, and M. Ye, "One step hydrothermal synthesis of $\mathrm{TiO}_{2}$-reduced graphene oxide sheets," Journal of Materials Chemistry, vol. 21, pp. 3415-3421, 2011.

[30] C. Nethravathi and M. Rajamathi, "Chemically modified graphene sheets produced by the solvothermal reduction of colloidal dispersions of graphite oxide," Carbon, vol. 46, pp. 1994-1998, 2008.

[31] M. Jevtić, M. Mitrić, S. Škapin, B. Jančar, N. Ignjatović, and D. Uskoković, "Crystal structure of hydroxyapatite nanorods synthesized by sonochemical homogeneous precipitation," Crystal Growth \& Design, vol. 8, pp. 2217-2222, 2008.

[32] P. Lian, X. Zhu, S. Liang, Z. Li, W. Yang, and H. Wang, "Large reversible capacity of high quality graphene sheets as an anode material for lithium-ion batteries," Electrochimica Acta, vol. 55, no. 12, pp. 3909-3914, 2010.

[33] S. Park, J. An, I. Jung et al., "Colloidal suspensions of highly reduced graphene oxide in a wide variety of organic solvents," Nano Letters, vol. 9, pp. 1593-1597, 2009.

[34] S. Koutsopoulos, "Synthesis and characterization of hydroxyapatite crystals: a review study on the analytical methods," Journal of Biomedical Materials Research, vol. 62, pp. 600-612, 2002.

[35] L. M. Malard, M. A. Pimenta, G. Dresselhaus, and M. S. Dresselhaus, "Raman spectroscopy in graphene," Physics Reports, vol. 473, pp. 51-87, 2009.

[36] M. S. Dresselhaus, A. Jorio, M. Hofmann, G. Dresselhaus, and R. Saito, "Perspectives on carbon nanotubes and graphene Raman spectroscopy," Nano Letters, vol. 10, pp. 751-758, 2010.

[37] K. N. Kudin, B. Ozbas, H. C. Schniepp, R. K. Prud'homme, I. A. Aksay, and R. Car, "Raman spectra of graphite oxide and functionalized graphene sheets," Nano Letters, vol. 8, pp. 36-41, 2008.

[38] A. C. Ferrari, "Raman spectroscopy of graphene and graphite: disorder, electron-phonon coupling, doping and nonadiabatic effects," Solid State Communications, vol. 143, no. 1-2, pp. 47-57, 2007.

[39] M. Markovic, B. O. Fowler, and M. S. Tung, "Preparation and comprehensive characterization of a calcium hydroxyapatite reference material," Journal of Research of the National Institute of Standards and Technology, vol. 109, pp. 553-568, 2004.

[40] G. Wang, J. Yang, J. Park et al., "Facile synthesis and characterization of graphene nanosheets," The Journal of Physical Chemistry C, vol. 112, pp. 8192-8195, 2008.

[41] I. Mobasherpour, M. S. Heshajin, A. Kazemzadeh, and M. Zakeri, "Synthesis of nanocrystalline hydroxyapatite by using precipitation method," Journal of Alloys and Compounds, vol. 430, pp. 330-333, 2007.

[42] M. Jevtić, M. Mitrić, S. Škapin et al., "Crystal structure of hydroxyapatite nanorods synthesized by sonochemical homogeneous precipitation," Crystal Growth \& Design, vol. 8, pp. 2217-2222, 2008.

[43] C. Nethravathi and M. Rajamathi, "Chemically modified graphene sheets produced by the solvothermal reduction of colloidal dispersions of graphite oxide," Carbon, vol. 46, no. 14, pp. 1994-1998, 2008.

[44] S. Pan, X. Liu, and X. Wang, "Preparation of $\mathrm{Ag}_{2}$ S-Graphene nanocomposite from a single source precursor and its surfaceenhanced Raman scattering and photoluminescent activity," Materials Characterization, vol. 62, no. 11, pp. 1094-1101, 2011.

[45] B. Bourgeois, O. Laboux, L. Obadia et al., "Calcium-deficient apatite: a first in vivo study concerning bone in growth," Journal of Biomedical Materials Research, vol. 65, pp. 402-408, 2003.

[46] Z. Zhang, H. Chen, C. Xing et al., "Sodium citrate: a universal reducing agent for reduction/decoration of graphene oxide with au nanoparticles," Nano Research, vol. 4, pp. 599-611, 2011.

[47] J. Shen, M. Shi, B. Yan et al., "Covalent attaching protein to graphene oxide via diimide-activated amidation," Colloids and Surfaces B: Biointerfaces, vol. 81, no. 2, pp. 434-438, 2010.

[48] Y. Li, W. Gao, L. Ci, C. Wang, and P. M. Ajayan, "Catalytic performance of Pt nanoparticles on reduced graphene oxide for methanol electro-oxidation," Carbon, vol. 48, pp. 1124-1130, 2010.

[49] L. Shao, S. Quan, Y. Liu, Z. Guo, and Z. Wang, "A novel "gelsol" strategy to synthesize $\mathrm{TiO}_{2}$ nanorod combining reduced grapheme oxide composites," Materials Letters, vol. 107, pp. 307310, 2013

[50] S. Stankovich, D. A. Dikin, R. D. Piner et al., "Synthesis of graphene-based nanosheets via chemical reduction of exfoliated graphite oxide," Carbon, vol. 45, no. 7, pp. 1558-1565, 2007.

[51] I. Mobasherpour, M. S. Heshajin, A. Kazemzadeh, and M. Zakeri, "Synthesis of nanocrystalline hydroxyapatite by using precipitation method," Journal of Alloys and Compounds, vol. 430, no. 1-2, pp. 330-333, 2007. 

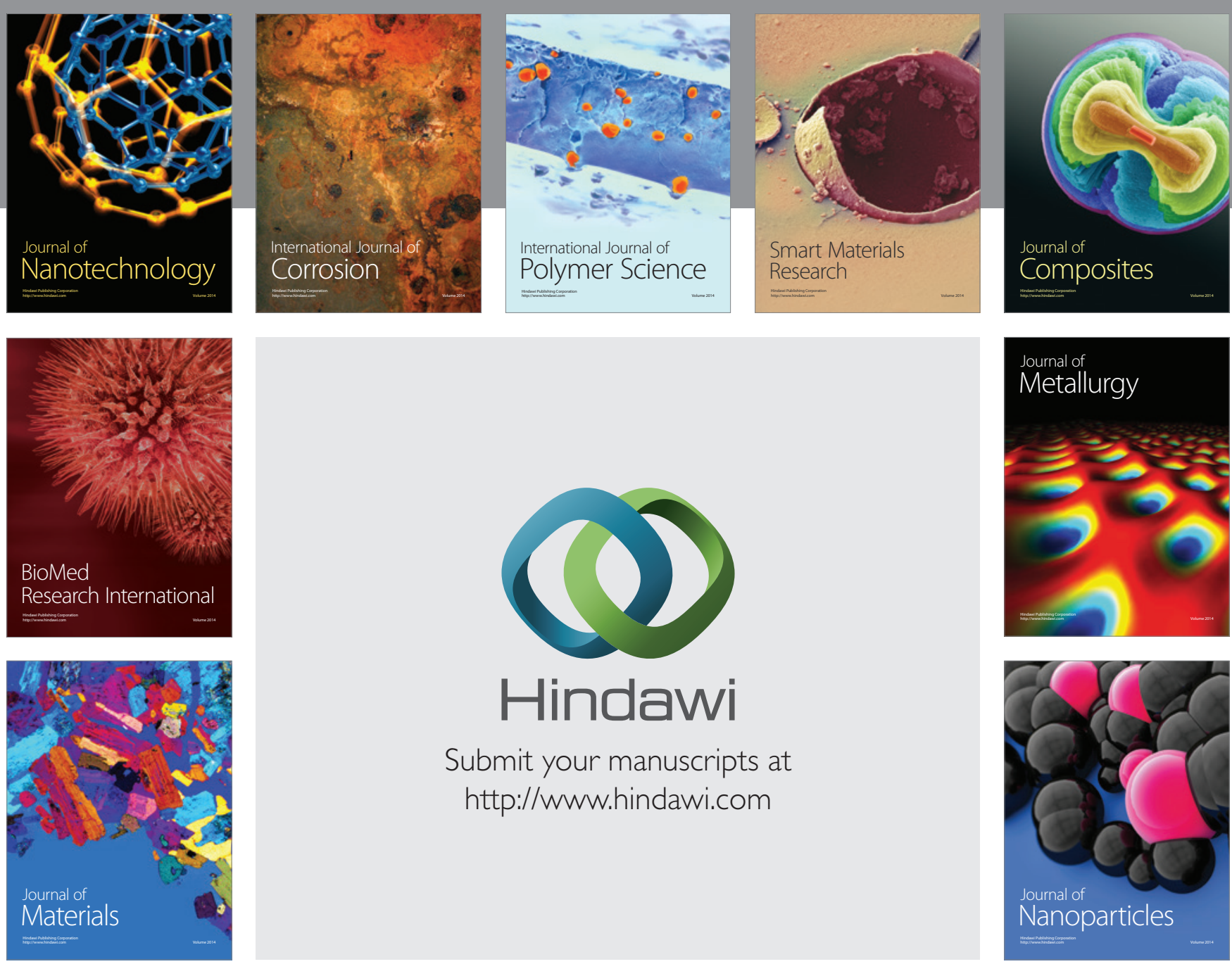

Submit your manuscripts at http://www.hindawi.com
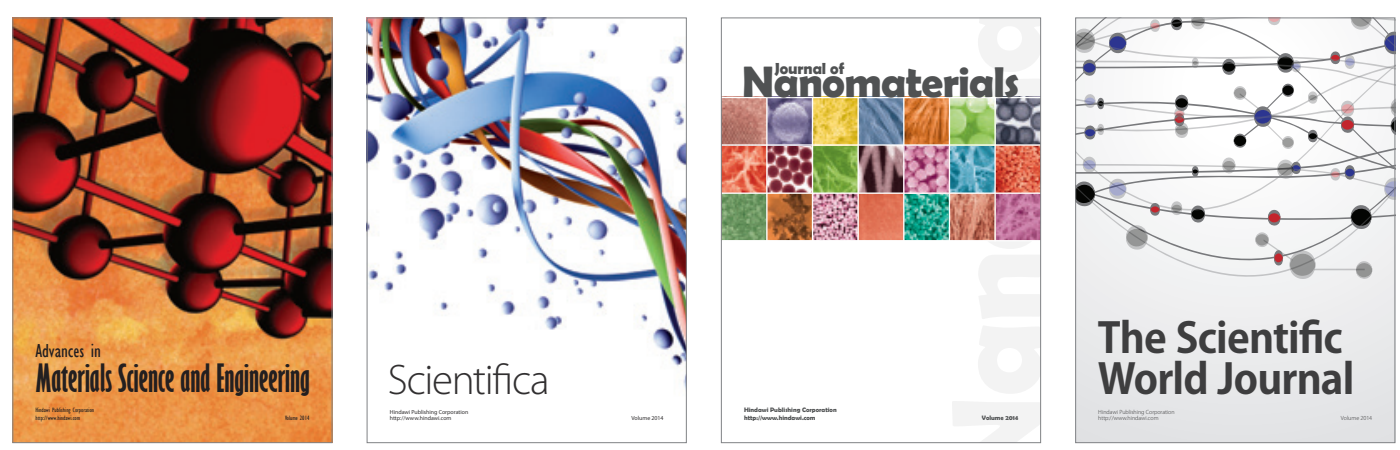

\section{The Scientific World Journal}
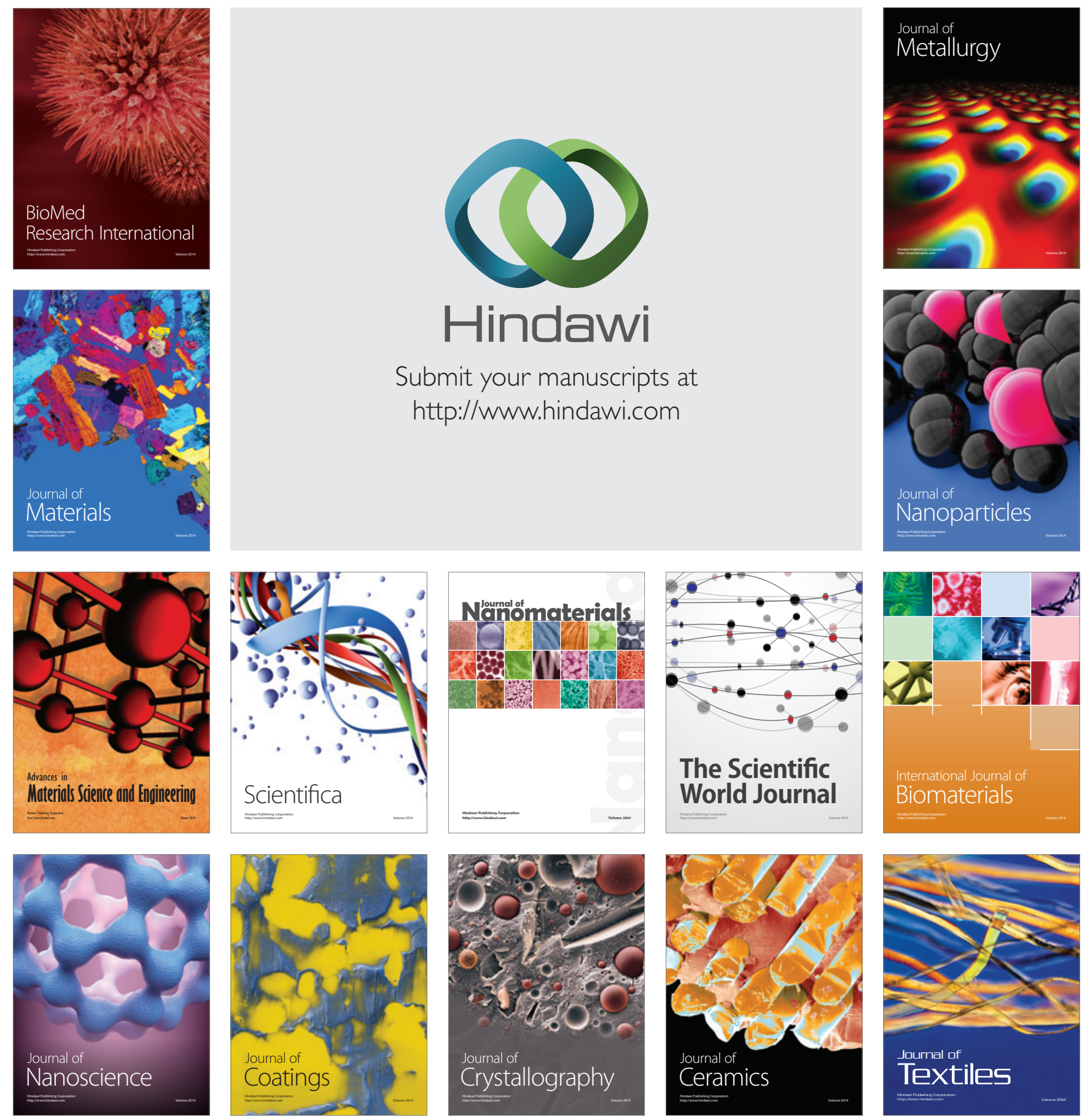